\title{
INVESTIGATING UNDERGRADUATE STUDENTS' PERCEPTIONS OF STUDYING POETRY
}

\author{
Diana PRESADĂ, Ph.D., Mihaela Badea, Ph.D., \\ Universitatea Petrol - Gaze din Ploiesti, \\ dianapresada@yahoo.com, \\ mihaelagab@yahoo.com
}

\begin{abstract}
The present paper aims at identifying philology undergraduates' perceptions of the courses and seminars during which they study poetry as part of their literature classes. By means of a questionnaire, whose data are both quantitatively and qualitatively interpreted, the study tries to answer questions such as: to what extent do students appreciate the study of poetry, do they consider the study of poetry useful for their own development and for their future career and if their teachers apply active learning strategies during their poetry classes.
\end{abstract}

Keywords: poetry, perception, undergraduates, teaching

\section{Introduction}

To turn poetry into a basic part of students' reading habits is an ideal of any language teacher, no matter the level of instruction he/she is involved in, primary school, high school or higher education. What makes poetry unique, and consequently the teaching of it, is that it "can make us feel more in tune with ourselves" (Naylor, Wood, 2012: 9) as well as with others. If taught properly and systematically, poetry offers numerous formative advantages as it has the power to stimulate imagination and creativity in students, to cultivate their empathy with the experiences of others, and to develop more positive attitudes towards life (Williams, 2012). The experience of a lyrical text results in personal renewal and self-awareness, which are the prerequisites for developing social responsibility and a proactive relationship to the world in general (Williams, 2012). Other researchers emphasize the idea that the teaching of poetry, which is a form of education through emotion, can mould students' consciousness by developing "aesthetic appreciation and the ability to communicate and value - beauty (or its absence) in our lives" (Quinlan, 2016: 263). 
As the educational potential of poetry is widely recognized, poetry is studied at all key stages of the instructional process offering teachers limitless classroom practices, or, as Sedgwick asserts, "each poem presents itself differently and introduces its own vast array of teaching possibilities" (2003: 51). Classroom practices may be based on various approaches to teaching poetry. For instance, Naylor and Wood identify a traditional model of teaching poetry, which focuses more on the text and less on the historical and cultural context that determined its creation (2012: 12-13), and the personal growth model, which lays emphasis on the development of the individual's imaginative and aesthetic life (2012: 13). They also mention the important contribution of Louise Rosenblatt who brings to the fore the reader's experience of a literary work showing that "the interpretation of texts is an active process, [and] that the reader is of equal importance in the creation of meaning as the work itself" (2012: 15). Other researchers speak of a holistic view of literature teaching that associates the subjective level of the personal growth model with an objective one consisting in the development of knowledge of the cultural heritage that poetry and literature in general encapsulate (Atherton et al.). In such a view, the concepts of personal growth and cultural heritage are interrelated with the concept of cultural analysis, which requires students "to place their experience of the texts in the context of broader ideas about history, meaning and function of literature in society, the values associated with it, and the roles it plays in their own lives" (2013: 6). Nevertheless, many teachers lay great stress on students' personal response to the text and pay little attention to cultural analysis. As this approach is "under-theorised" and does not aim to develop students' ability "to locate their subjective responses critically in contemporary socio-cultural contexts" (2013: 5), it has been argued that a more theorised teaching style able to engage students in more objective and critical discussions of canonical texts would be necessary (2013: 5). As a matter of fact, a successful study of poetry requires an integrated approach in which attention should be equally paid to textuality, language and culture. It is a student-centred approach that values students' personal and critical response to poetry, actively engaging them in analysing the meaning and significance of the text both in discussion and in writing. Implicitly, such an approach aims to develop students' awareness of the theoretical aspects related to the taught subject and the complex relationships among text, language and culture, or reader, writer and text.

In a poetry class, the teacher should play the role of "a guide to the art of poetry" and not of a "guardian of meanings" (Wormser and Cappella, 2009: 339). In this quality, the teacher-facilitator encourages students to explore the style of the poem and take part in intelligent critical discussions. As Wormser and Cappella rightly show, "style is meaning in poetry" (2009: 
346), which implies the idea that any discussion of meaning is simultaneously a discussion of form. In other words, content and form are inseparable in poetry, or, as the same authors put it, by discovering "rhythm, words choice, form and metaphor, you are going to be talking about meanings" (2009: 346). It has often been argued that a poem is difficult to understand and analyse, but the key to a successful approach is to work through its form to discover its meaning. In this sense, Stephen Burt specifies that "All poetry is difficult if you don't have a way in, a sense of what's represented how (which allows you to ask why)" (2010: 20). The study of poetry, which is always based on a movement from the outside towards the inside, means, therefore, "Starting with words and forms and working toward the students' felt experience" (Duke and Jacobson, 1992: 107). Used as a playground for intellectual, emotional and cultural exploration, poetry becomes an effective "way of developing personal values, understanding multicultural heritage, and broadening experience" (Ruurs, 2000: 8).

\section{Methodology}

\subsection{Research questions}

The purpose of the research is to evaluate undergraduate students' perceptions of the study of poetry during their literature courses and seminars, as well as outside the classroom. The following questions lay at the basis of the research:

1. To what extent do students appreciate the study of poetry?

2. Do teachers apply active learning strategies during their poetry classes?

3. Do students consider the study of poetry useful for their own development and for their future career?

\subsection{Participants in the study}

As the study ofpoetry is a major component of the Philology curriculum, 69 students were invited to participate in the research. They are final year students specialising in Romanian and English language and literature at the Petroleum - Gas University of Ploiesti. All of them studied poetry in the first, the second and the third year of study.

\subsection{Research instrument}

The research used quantitative methods, the main research instrument being a questionnaire that consisted of 10 items. It included 3 closed questions, 1 semi-open question and 6 open questions. The information offered by students' answers to these items was analysed both quantitatively and qualitatively in order to get a general image of the way in which poetry is taught and perceived at university level. Instructors interested in teaching 
poetry may find in the collected data useful suggestions for the improvement of their own courses and seminars.

\section{Data Analysis}

Students' answers to the questionnaire offered relevant information that was analysed as follows. As shown in the table below and in figure 1, a large proportion of the respondents $(82.61 \%)$ have a favourable opinion of their poetry courses and seminars. Such a high percentage is not surprising as they have the opportunity to study a variety of poems belonging to all periods of time and corresponding to all interests or literary tastes. Their positive perception of poetry may also be explained by the fact that, alongside canonical texts and authors, they study particular poets and texts during their optional courses and seminars. In some cases, the syllabus of optional poetry classes is based on students' preferences in terms of authors and poems.

\begin{tabular}{|l|l|l|}
\hline \multicolumn{3}{|c|}{ Q1. Do you appreciate your poetry classes? } \\
\hline & No. & $\%$ \\
\hline Yes & 57 & $82.61 \%$ \\
\hline No & 12 & $17.39 \%$ \\
\hline
\end{tabular}

Do you appreciate your poetry classes?

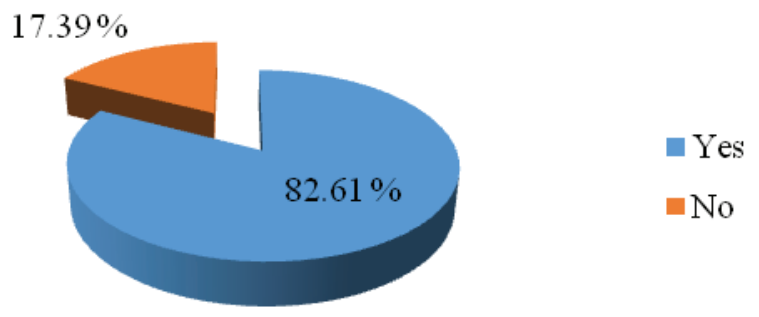

Figure 1. Students' opinions of poetry classes

According to question two (What teaching strategies does your teacher use? Enumerate some of them.), students' answers showed that they appreciate poetry courses or seminars because their instructors use a variety of teaching strategies and methods, which have a great motivating potential. As far as courses are concerned, students generally identified active learning strategies such as brainstorming, free discussion, debate, problem-solving, etc., which demonstrates that teachers have implemented the student-centred 
model of learning in the lectures. As regards the seminars, respondents pointed out their interactive quality by mentioning the frequent use of pair or group work. They also appreciate the fact that their teachers clarify and explain the meaning of difficult poems, and that the textual analysis performed in pairs or groups helps them to better understand the significance of a poem.

As regards question three (What teaching aids does the teacher use? Enumerate some and explain why they are necessary.) students' responses confirm that most teachers bring works of critics into the classroom to illustrate or comment on various theoretical aspects related to poetry and textual analysis. They find these books extremely useful because they help them to understand long intricate poems, especially symbols and imagery that are hard to decipher. At the same time, they are dissatisfied with the fact that video projectors, power point presentations and handouts are rarely used. They are of the opinion that these teaching aids help them to better understand teachers' explanations and complicated critical theory.

The questionnaire also aimed to find out students' opinions about their poetry syllabus. According to the table below and figure 2, a high percentage of the respondents $(79.71 \%)$ appreciate the content of their poetry courses and seminars, most of them considering the syllabus very interesting and interesting. It should be noted that these views reinforce the responses to question 1 , discussed above.

\begin{tabular}{|l|l|l|}
\hline \multicolumn{3}{|l|}{ Q4. How do you find your poetry syllabus? } \\
\hline & No. & $\%$ \\
\hline Very interesting & 21 & $30.43 \%$ \\
\hline Interesting & 34 & $49.28 \%$ \\
\hline Boring & 14 & $20.29 \%$ \\
\hline
\end{tabular}

How do you find your poetry syllabus?

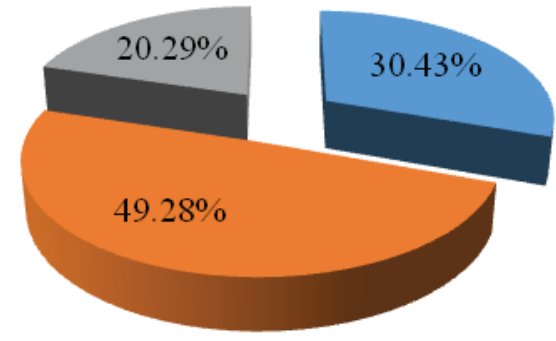

घery interesting

interesting

- boring

Figure 2. Students' opinions of the poetry syllabus 
The answers to question five (What are the benefits of poetry classes? Specify some of them.) show that students are aware of the instructional advantages of the study of poetry. Most of them believe that such classes help them to enrich their knowledge and culture, increase their understanding of the world, develop their thinking and language skills, etc. Apart from the intellectual aspects that poetry entails, respondents appreciate it for its emotional and affective qualities, as shown by answers such as: "poetry teaches us how to live, to love and feel", "poetry helps you when you are sad, lonely or misunderstood", "we discover the beauty of literature in an enjoyable way", etc.

The questionnaire also included a question (Q 6. Which are the weaknesses of poetry classes? Enumerate some of them.) meant to identify the negative aspects related to poetry classes. Students' answers reveal that, although they like the content of their syllabus, they do not have enough time for reading all the materials required by teachers (poems or literary criticism) or for finishing the projects required within such classes. Among the factors that hinder them to complete their assigned tasks are the great number of poets and poems they have to read, their overloaded timetable in general and the bibliography they must study for other disciplines of the curriculum. Others dislike long and difficult poems whose meaning remain obscure in spite of their efforts to decipher it. Another problem mentioned by respondents is that some students, especially when they cannot understand the teacher's explanations, get bored and noisy disturbing the flow of the lesson. According to them, such events happen when lectures are too theoretical and the information presented by teachers is too dense.

As to question seven referring to the measures that instructors should take to improve these courses and seminars, the majority of the students agree that teachers should simplify and synthesize the theoretical aspects related to the study of poetry. They believe that unimportant details and complicated information should be avoided during poetry classes. It is notable that some respondents consider the use of humour to be the best way to engage students in the learning process. Some respondents also believe that poetry classes would be more effective if teachers chose short poems instead of long unattractive texts that are time-consuming and more difficult to read.

The answers to question eight revealed students' perceptions of poetry compared to novel and drama. As indicated in the following table and in figure 3, the majority $(65.22 \%)$ considers that the study of poetry is not as interesting as the study of the novel and drama. This attitude may be explained by the fact that students believe that poetry is more difficult to understand and interpret than prose and plays. Moreover, they tend to identify themselves with the characters in novels and plays much easier than with an abstract voice in a poem. 
Q. 8. Do you find studying poetry as interesting as studying the novel and drama?

\begin{tabular}{|l|l|l|}
\hline & No. & $\%$ \\
\hline Yes & 24 & $34.78 \%$ \\
\hline No & 45 & $65.22 \%$ \\
\hline
\end{tabular}

Do you find studying poetry as interesting as studying novel and drama?

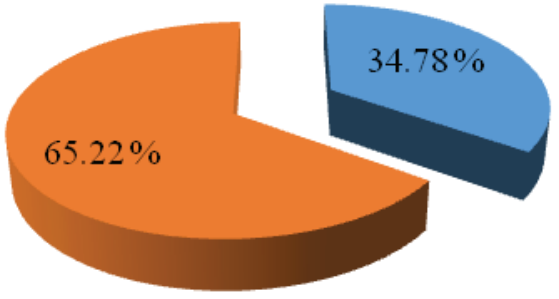

Figure 3. Students' perceptions of poetry vs. the novel and drama

Although the majority of the respondents enjoy poetry classes and are aware of their formative quality, their answers to question nine (How much time do you spend on reading poetry outside the classroom?) show that they rarely read poetry during their spare time. Most of them admit that they read only the poems included in the bibliography required for courses and seminars. It should be stressed that very few students like reading poems for pleasure and on a regular basis. In general, students' lack of interest in reading poetry outside the classroom can be explained by the fact that they prefer reading novels or plays. On the other hand, a low number of respondents never read poetry in their spare time on the grounds that they "dislike it" or they ,don't feel attracted to it".

With respect to question ten, the authors of the present study intended to find out students' opinions about the educational potential of poetry classes in relation to the career they will choose in the future. The findings are shown in the table below and in figure 4.

Q10. Do you think that poetry classes will help you in your future career? Justify your point of view.

\begin{tabular}{|l|l|l|}
\hline & No. & $\%$ \\
\hline Yes & 42 & $60.87 \%$ \\
\hline No & 27 & $39.13 \%$ \\
\hline
\end{tabular}


Do you think that these classes will help you in your future career?

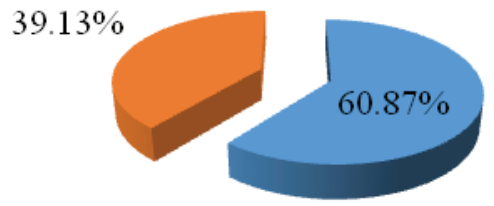

Figure 4. Students' views on the usefulness of poetry classes

As indicated above, the majority of the respondents (60.87\%) believe that poetry classes are very useful because "they prepare you for your future career". As most of them will become English or Romanian language and literature teachers, it is important for them to have solid knowledge about canonical texts, modern and contemporary poetry. In addition, they believe that the textual analyses performed during the poetry classes, particularly the seminars, are of great help because they develop their ability to analyse and reflect critically on various poetic texts. In this way, they "will know how to deal with a text and explain it to the pupils". As to the proportion of students (39.13\%) who consider that poetry classes are not necessary for their future career, their opinions are justified by the fact that they dislike the teaching career and prefer being employed in a different field. They consider that the study of poetry is useful only for those who want to work in education and not for those who will choose other career paths.

\section{Conclusions}

The findings of the present study provided positive answers to the three research questions. A large majority of the students (82.61\%) enjoy their poetry courses and seminars, and a high percentage of them $(60.87 \%)$ believe in the formative and lasting influence of poetry in their professional development as future teachers. They also appreciate that poetry classes are student-centred and based on active learning strategies that motivate their participation in the instructional process.

On the other hand, the fact that most learners rarely read poetry for pleasure outside the classroom demonstrates that they have not fully internalized the benefits of poetry. In such a context, it may be argued that one of the priorities of poetry classes is to cultivate a lifelong habit of reading poetry in students. To achieve this purpose, as learners themselves suggested, teachers should rethink their poetry classes by adapting theoretical information to students' needs, laying more emphasis on in-depth 
studies and less on comprehensive topics, including in the syllabus not only canonical poets but also what students prefer reading, avoiding overloaded assignments, etc. Moreover, to change learners' perception that poetry is a difficult genre, creative writing classes may be a good option as they enable them to study poetry starting from their own writing experiences. If poetry is appropriately taught and students are motivated, they may rediscover its beauty and enjoy it in the same way as they enjoy prose and drama. No matter what career they choose, students that have a more practical view on life may come to value poetry and read it for pleasure.

\section{References:}

Atherton, C., Green, A., Snapper, G. (2013). Teaching English Literature 1619, An Essential Guide. London and New York: Routledge, Taylor and Francis Group.

Burt, S. (2010). "How to Teach 'Difficult' Poetry and Why It Might Not Be Difficult after All", in Poets on Teaching, A Sourcebook. Wilkinson, J., M. (ed.). Iowa City: University of Iowa Press.

Duke, C. R., Jacobsen, S. A. (Eds). (1992). Poets' Perspectives: Reading, Writing, and Teaching Poetry. Portsmouth, NH: Heinemann.

Naylor, A., Wood, A. B. (2012). Teaching Poetry: Reading and Responding to Poetry in the Secondary Classroom. London and New York: Routledge, Taylor and Francis Group.

Quinlan., K. M. (2016). How Higher Education Feels: Commentaries on Poems That Illuminate Emotions in Learning and Teaching. Rotterdam: Sense Publishers.

Ruurs, M. (2000). The Power of Poems: teaching the Joy of Writing Poems. Gainesville, FL: Maupin House Publishing, Inc.

Sedgwick, F. (2003). Teaching Poetry. London and New York: Continuum.

Williams, T. O. (2012). A Therapeutic Approach to Teaching Poetry. Individual Development, Psychology and Social Reparation. New York: Palgrave Macmillan.

Wormser, B., Cappella, D. (2009). Teaching the Art of Poetry, The Moves. Mahwah, New Jersey: Lawrence Erlbaum Associates, Inc. 